\title{
IT Professionals Awareness: Green IT International Comparison Study
}

\author{
Nathalia Devina Widjaja ${ }^{1}$, Minsani Mariani ${ }^{1}$ and Karen Imam $^{2}$ \\ ${ }^{1}$ school of information systems, Binus International University, Jakarta, Indonesia \\ ${ }^{2}$ School of Management, Binus International University, Jakarta, Indonesia
}

\begin{abstract}
Global warming and other environmental issues such as energy and resource constraint are becoming the world's major concerns and need to be solved. Information Technology (IT) is perceived as an enabler to resolve those problems and bring greater efficiency. This concept is known as Green IT which covers energy conservation by IT and energy conservation of IT. It is important to analyse the awareness of IT professionals about Green IT in order to measure whether they are ready to implement a Green IT strategy. Many countries have already applied Green IT initiatives to reduce carbon emissions. Awareness of Green IT has been measured in many countries, except Indonesia, which has committed to reduce its carbon emissions by $26 \%$ in 2020. Green IT should be one of the potential enablers to achieve that goal. This paper provides a preliminary insight into Green IT awareness among Indonesian IT professionals and shows a comparison between attitude and awareness levels of other countries. Some recommendations will be discussed in order to increase the awareness and reduce the inhibiting factors that influence it. The current findings suggest that although IT professionals in Indonesia have already some concerns about climate change and the power consumption of IT, there is still a lack of implementation and action dimensions.
\end{abstract}

Keywords: Green IT, Carbon Emissions, Readiness, Awareness.

\section{Introduction}

\section{Definition}

In a world of continuing innovation and high dependency on new technology, ICT is an essential component of corporate infrastructure and organization. Parallel to this, environmental issues motivate new brand image strategies and increase the competitiveness of most multinational companies as international regulation becomes stronger.

Green IT appears to be the right element to connect both corporate innovation and environmental integration. As stipulated by the National IT and Telecom Agency in the "Green IT guidelines for public authorities" (2008), Green IT can be included in each of the four phases of the product lifecycle:
1) The development phase includes the design of environmentally friendly systems and computers by using green material and seeking energy efficiency consumption.

2) The production phase focuses on energy saving and the reduction of carbon emissions. The first deals with cost saving while the second takes an environmental approach. On one hand, producing at lower costs aims to use less energy, on the other hand reducing the $\mathrm{CO} 2$ emission tends to use subsidized energy sources such as solar panels.

3) The Usage phase refers to the organization itself, employee behavior, equipment and infrastructure. To implement a Green IT strategy, the

Copyright (C) 2011 Nathalia Devina Widjaja, Minsani Mariani and Karen Imam. This is an open access article distributed under the Creative Commons Attribution License unported 3.0, which permits unrestricted use, distribution, and reproduction in any medium, provided that original work is properly cited. Contact author: Nathalia Devina Widjaja E-mail: nwidjaja@binus.edu 
management needs to draw up a new process and implement new standards not only in terms of IT infrastructure but also in terms of individual usage such as printing work, employee green behavior, recycling paper and electricity usage.

4) The Disposal phase is the most critical phase as it mainly depends on the government's participation to enforce regulations and motivate companies to invest in product which can have a second life.

Nowadays Green ICT concerns have grown beyond being just a trend, to becoming a priority, especially for the government which needs to achieve considerable reductions of carbon emissions and cost savings.

\section{International Background}

Governments have already tried to implement Green IT models. In the following paragraphs Europe, Australia and USA will be mentioned as examples.

\section{1) Europe}

As stipulated by the European Commission in its Code of Conduct on Data Centers Energy Efficiency (2008): "Many data centers operators are simply not aware of the financial, environmental and infrastructure benefits to be gained from improving the energy efficiency of their facilities. Even awareness does not necessarily lead to good decision making, simply because there is no framework in place for the operators to aspire to. Making data centers more energy efficient is a multidimensional challenge that requires a concerted effort to optimize power distribution, cooling infrastructure, IT equipment and IT output."

This code of conduct takes into consideration two dimensions of data centers. Firstly IT Loads which concerns the energy consumption of IT equipment itself, and secondly facility loads which concerns those elements supporting the IT equipment; such as cooling systems and air conditioning. It aims to minimize the energy consumption of ICT by committing the data centers owners and operators as well as the suppliers and service providers.

\section{2) $\boldsymbol{U S A}$}

In the United States, The Environmental Protection Agency has launched its Environmentally Preferable Purchasing Program (EPP) since 1993. As explained on the EPA website (2010): "EPP helps the federal government "buy green," and in doing so, uses the federal government's enormous buying power to stimulate market demand for green products and services." As far as IT is concerned, EPP supports IT equipment suppliers who have fulfilled the green standards applied by EPA and promotes Software to measure the energy consumption and efficiency of data centers and IT supplies.

\section{3) Australia}

Closer to Southeast Asia, Australia is a good example of Green IT integration. The government has taken serious initiatives to position Australia as one of the most proactive nations in terms of Green ICT. Based on the information shared by the Department of Finance and Deregulation on the website of the Australian government (2010), the Australian government has developed some guidelines for the private and public sector. The main priorities listed include some basic changes like the usage of black screens or static screen savers instead of active screensavers or the necessity to provide automatic shutdown of desktop and laptop fleet after hours. Moreover agencies are encouraged to measure power consumption of ICT as a component of total power use as well as using tools and practices to assist employees in reducing the number of printed pages per employee per month. Finally, agencies are advised to replace inefficient monitors at the end of their life cycle with more energy-efficient models (e.g. replace CRT monitors with more energy efficient alternatives) and finally they are requested to undertake a telephone refresh to consider technologies that optimize energy use efficiency and 
minimize duplication of handsets per employee. Long term goals provide a realistic idea of the future steps to follow for a successful Green IT implementation. Case studies provide useful examples - thin client and virtualization, creation of energy efficiency standards, and the introduction of a carbon calculator for meetings. As part of an important change in the policies and strategy of companies and governments, a recent study published by www.thegreenitreview.com (2010), showed that $18.8 \%$ of the ICT carbon footprint in Australia in 2009 came from data centers. This report, developed by Connection Research for the Australian Computer Society (ACS) showeddetails of the energy consumption and carbon footprint of ICT usage in Australia plus an examination of how ICT can act as a lowcarbon enabler. It emphasizes the way to improve energy efficiency using, for example, the support of the Australian Information Industry Association (AIIA).

Moreover, the report offers advice on the emergence of new competitors and the need in the near future to create strategic alliances and build stronger and more reliable programs.

\section{4) Indonesia}

Based on the Ministry of Finance, "Economic and Fiscal Policy Strategies for Climate Change Mitigation in Indonesia" (2009), Indonesia agreed during the Climate Change conference in Copenhagen in 2009, to take action to reduce greenhouse gas emission by a range between $26 \%$ and $41 \%$ by 2020 . However the government strategy has not yet integrated IT as a potential environmental issue.

\section{Research Methodology and Objectives}

The first part of this paper provides a preliminary insight into Green IT awareness among Indonesian IT professionals. The second part offers a comparison between the results from part one and the attitude and awareness level in other countries. This research is largely descriptive and based on a survey response from 105 Indonesian IT professionals from a cross section of different industries. The survey was conducted by over 1000 professionals from May to July 2010. The questionnaire was uploaded to a website, to allow participants to easily access the survey.

Similar studies have been done such as "Green IT Diffusion: an international comparison" written by A. Molla, S. Pittayachawan, and R. Corbitt, and published by RMIT University (2009) to assess the Australian market, and also by Info Tech to assess Europe, North America, Asia and other countries (2009). The research questions address the extent to which IT professionals are concerned about climate change and their perceptions of the contribution of IT and its role to tackle a business environmental footprint. In addition, the questions address what IT professionals have done to increase their awareness and readiness for Green IT.

The profile of survey participants was identified according to gender, age, occupation, and educational qualification. An ANOVA test was used to explore whether there were significant differences in participants" responses due to gender, age, occupation, and educational qualification differences. In addition, SPSS v.16 was used to test the reliability and validity of the collected data. 
Table I: Reability Statistic

\begin{tabular}{|l|c|}
\hline \multicolumn{1}{|c|}{ Item } & $\begin{array}{c}\text { Cronbach's Alpha } \\
\text { Based on Standardized } \\
\text { Items }\end{array}$ \\
\hline IT's impact on Environment & 0.60 \\
\hline Green IT Knowledge & 0.47 \\
\hline $\begin{array}{l}\text { IT professional's role in Green } \\
\text { IT }\end{array}$ & 0.80 \\
\hline Green IT Practice & 0.45 \\
\hline Green IT Commitment & 0.86 \\
\hline Action to Green IT & 0.88 \\
\hline Green IT Governance & 0.74 \\
\hline Personal Commitment & 0.82 \\
\hline
\end{tabular}

To assess instrument quality, the internal consistency reliability ( $\alpha$ coefficient) was calculated. Cronbach's alpha represents how the items were correlated as a group, and therefore the reliability of the research. Research is generally considered acceptable when it reaches a minimum level of 0.60. [9]. Based on Table I, the Cronbach's alpha of all categories exceeded 0.60 except for Green IT knowledge and Green IT practice.

To check the validity of the instrument, all of the corrected item-total correlation $(r$ table) should be greater than the calculated critical item ( $r$ calculated) which is 0.19. According to Table II, all of $r$ table is greater than 0.19; therefore all instruments are valid. Although the category Green IT knowledge and practice issues are not reliable, they are proven to be valid. There were two different types of questions asked regarding Green IT knowledge. One question asked about the intention to increase knowledge and the other asked about action to enhance knowledge. As explained in the content of this paper later on, there was still a gap between intention and action; therefore the respondents could not consistently answer the respective questions. In addition, a lack of news, and articles about the Green IT issue in Indonesia was also an influencing factor on the answers in this section. In Green IT practice, the questions concerned three different types of action. The results demonstrated that most of the respondents were only doing one of the actions and not all three at the same time. Therefore, the findings translated the answer as not focused on the core concept. However, those three questions are valid to measure this section since those actions were Green IT actions; examples include reducing the amount of paper used, energy efficiency, and the use of recycled IT equipment to reduce waste. Consequently, for the purpose of this research, Green IT knowledge and practice has still been included in the analysis. 
Table II: Validity Statistic

\begin{tabular}{ll}
\hline \multicolumn{1}{c}{ Item } & r \\
\hline $\begin{array}{l}\text { IT's Impact on Environment } \\
\text { I believe that IT equipment and systems contribute to green house gas } \\
\text { emission }\end{array}$ & 0.43 \\
I believe that IT can be used to reduce a business's total carbon footprint & 0.43 \\
Green IT Knowledge & \\
I read news and articles about Green IT issue & 0.23 \\
I am willing to learn / gather more information about Green IT issue & 0.31 \\
I have purposely attempted to attend a seminar or workshop on Green IT & 0.31 \\
IT Professional's Role in Green IT & 0.53 \\
I believe that IT management should be responsible for reducing IT's green & 0.70 \\
I believe that IT professional can play significant roles in helping tackle \\
business's carbon footprint
\end{tabular}




\section{Result}

Data for this survey came from the IBM customer database. A descriptive approach was used to analyse the data. Anova was used to analyse the significant differences between age, occupation, gender, education qualification and industry.

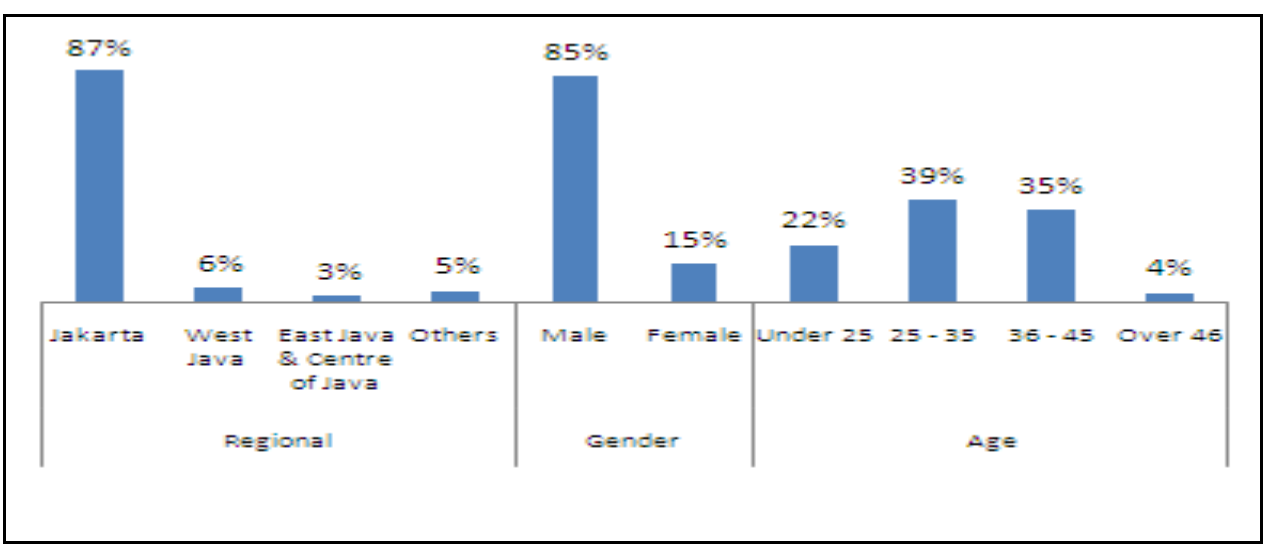

Figure 1. Respondents' Distribution

Based on the results shown in Figure 2, $87 \%$ of the respondents are from DKI Jakarta, more than $80 \%$ of the respondents are males and more than half are within the age bracket of $25-45$.

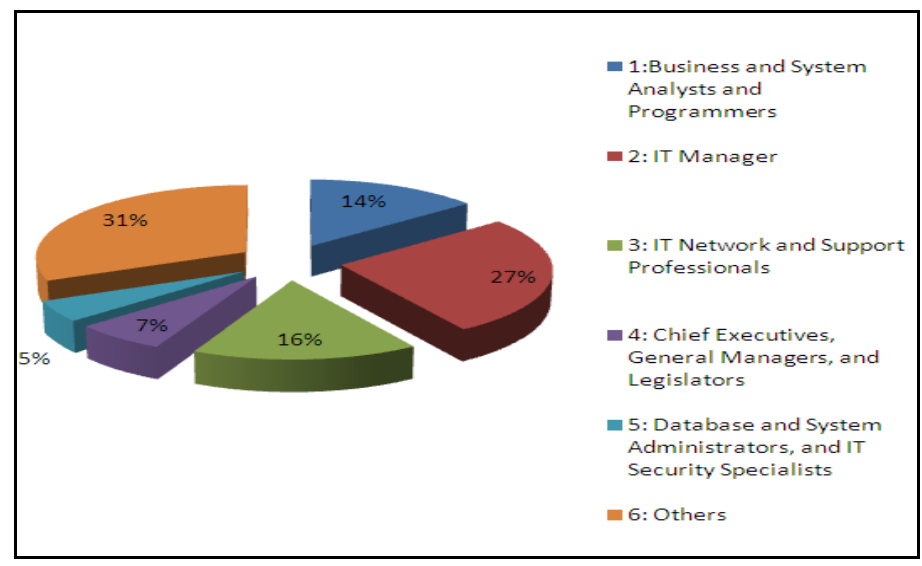

Figure 2. Respondent's Occupation

From figure 3, 31\% of the respondents have different occupations to the ones listed. Some of them are IT consultants, IT sales or IT lecturers. However, the rest of the respondents are IT Manager and IT Network and Support Professionals. 


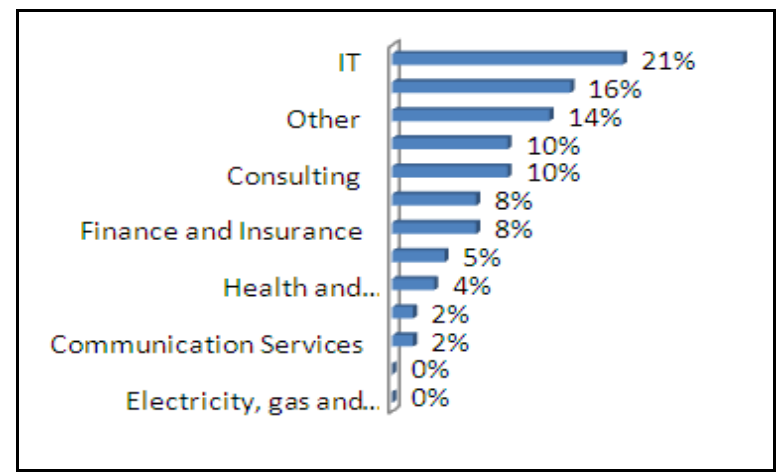

Figure 3. Respondent's Industry

As it can be seen in figure 4, most of the respondents are working in IT (21\%) or Education industry (16\%).

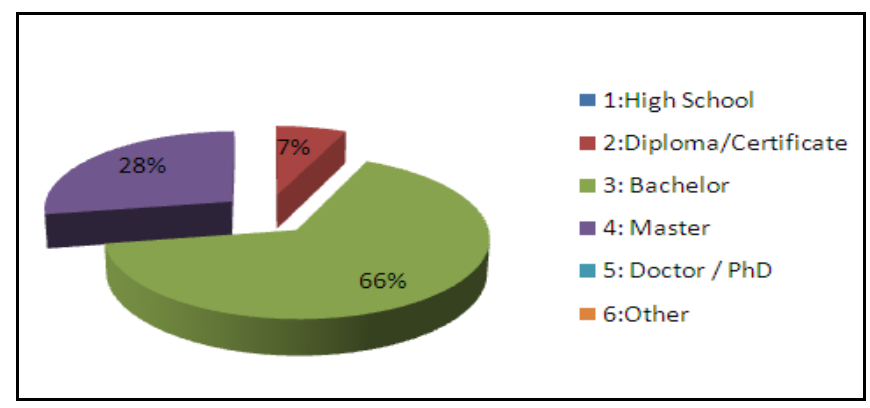

Figure 4. Educational Qualification of Respondents

The education background of the respondents is dominated by Bachelor degree graduates $(66 \%$ as shown in Figure 5). Following them are those with a Master degree and Diploma / Certificate. None had a Doctoral degree nor have any just graduated from high school.

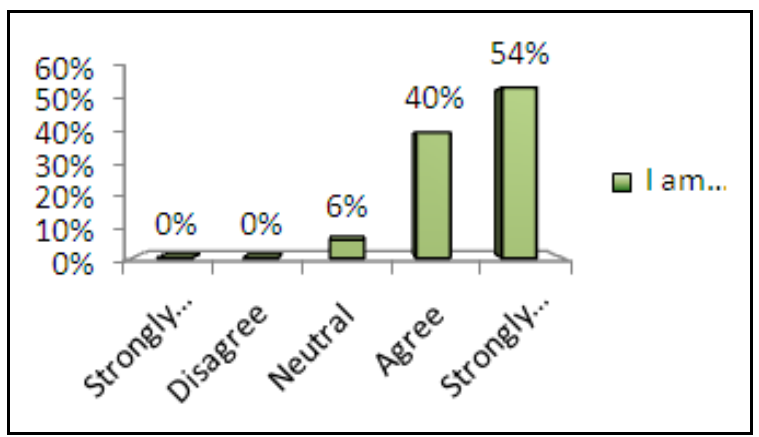

Figure 5. Opinion about Climate Change

More than $90 \%$ of our respondents are concerned about climate change. Climate change is related to global warming which is caused by $\mathrm{CO} 2$ gas emission. This high level of concern means that IT professionals in Indonesia are aware that something has to be done regarding this issue. In addition, there is no significant difference in terms of respondent's gender, age, industry, occupation or education background related to their response $(\alpha<=$ 0.05). 


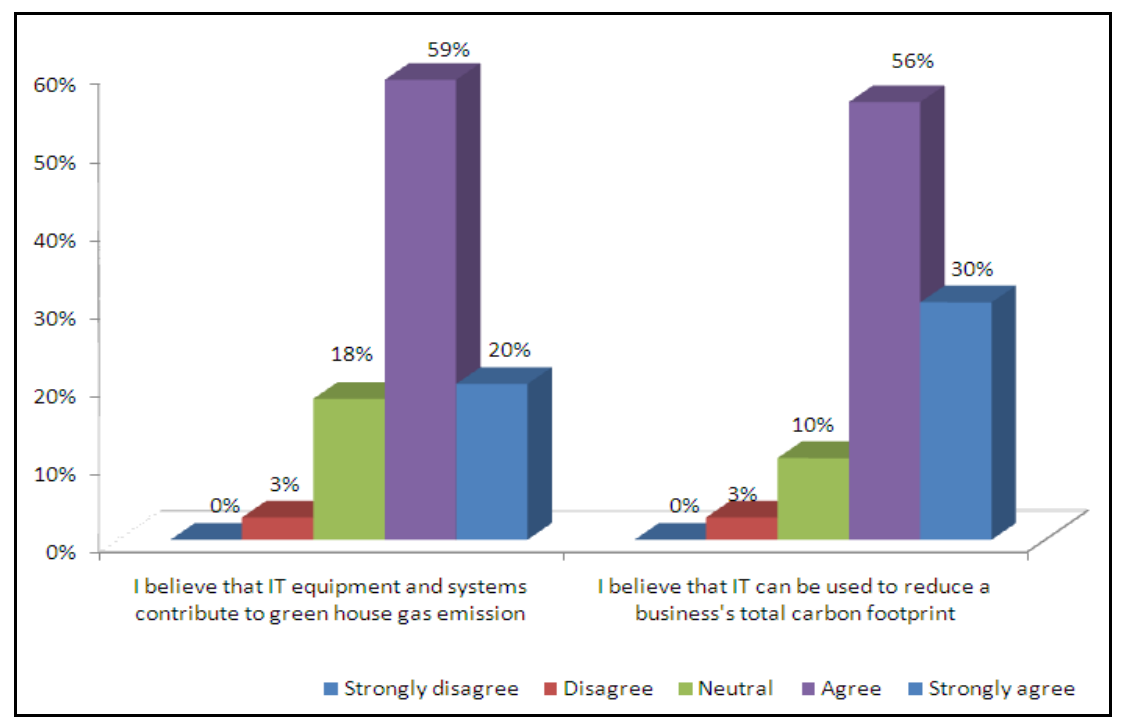

Figure 6. IT's Impact on Environment

More than $85 \%$ of the respondents believe that IT can impact carbon emissions either by producing or reducing a business's total CO2 gas as shown in Figure 7.
These views are not sensitive to differences in a participant's profile.

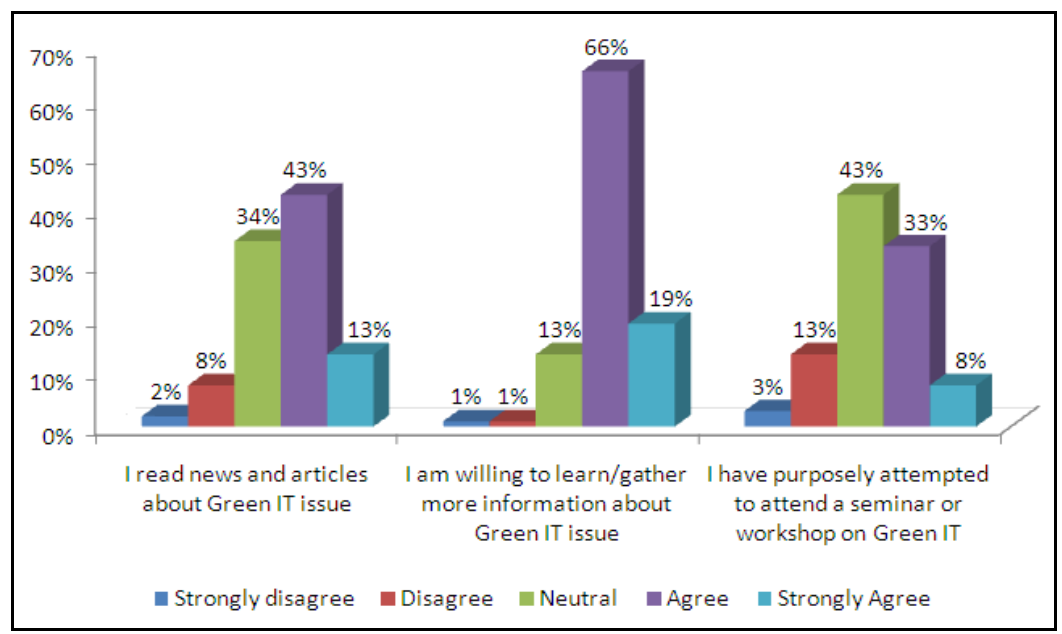

Figure 7. Green IT Knowlegde

Although more than $80 \%$ have intentions to learn more about Green IT issues, based on the result in Figure 8, less than 60\% read news and articles about this and less than $45 \%$ have purposely attempted to attend a seminar or workshop on Green IT. According to previous research [10], there is always a gap between intention and action. In this section, most IT professionals in Indonesia said that they have the intention to gather more information about Green IT; however only a limited number of people are interested in attending seminars or workshops to enhance their knowledge of Green IT. The lack of news and articles on the Green IT issue in Indonesia is also one of the reasons why only $56 \%$ of respondents read about it.

There is no significant difference in their anwers considering their location, industry 
and gender. However, in terms of position, IT managers and other positions that are not mentioned in the questionnaires tend to have both the willingness and have taken action to gain knowledge in Green IT. Also, people who have Master degrees and Bachelor degrees are statistically significantly different from one another. The respondents with Master degrees show more eagerness to read and participate in Green IT seminars. In addition, respondents who are less than 25 years old are less likely to have the intention and action to increase their Green IT knowledge level compared to people who are of a mature age (36 - 45 years old).

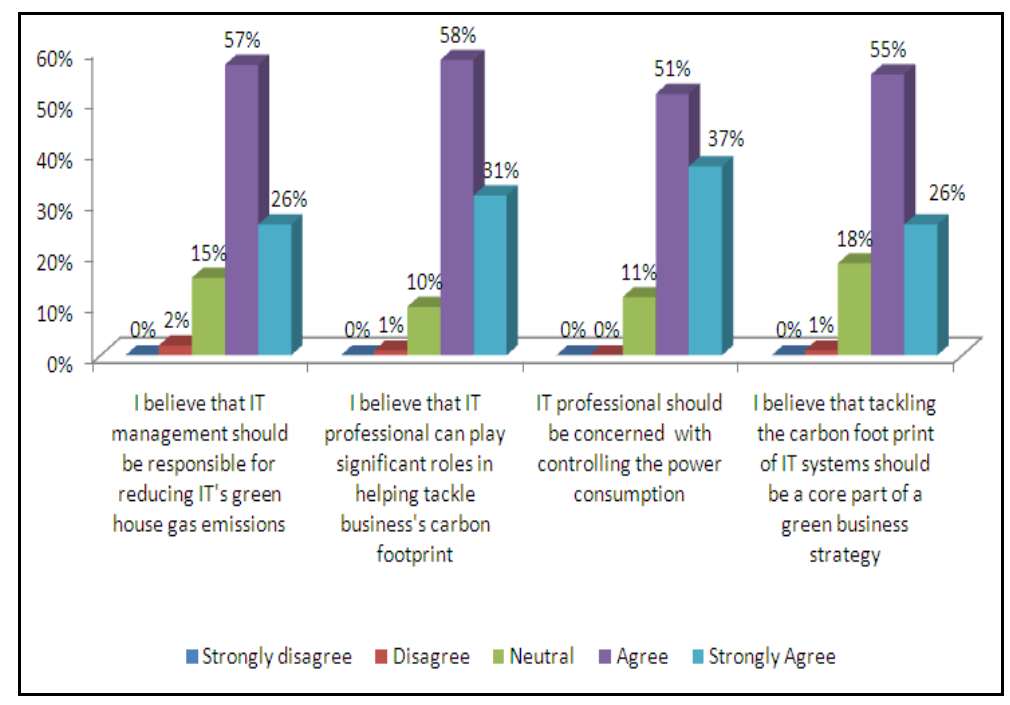

Figure 8. IT Professional's Role in Green IT

In this part, there were four questions given to respondents. Most IT professionals in Indonesia recognise their role in leading change in Green IT. And based on the result above, it is clear that both IT management and IT professionals have an important role and should take responsibility to reduce the green house gas emissions of the IT industry. IT management should support this action in the organisation and influence their employees. While at the same time, IT professionals should be concerned with the implementation part such as controlling power consumption. On top of that, most respondents agree that tackling the carbon foot print of IT systems should be a core part of an overall strategy for green business. There is no significant difference in their anwers considering their location, industry, age, occupation or gender. 


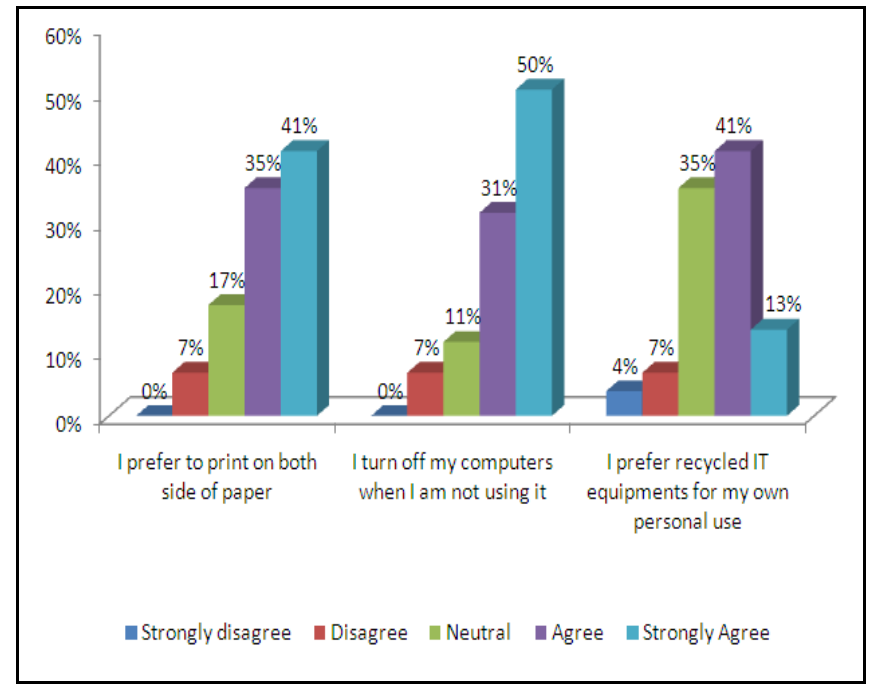

Figure 9. Green IT Practice

In this part, respondents were given three questions concerning their daily activities. $76 \%$ of them prefer to print on both side of paper and $81 \%$ of them turn off their computers when they are not using them. However, only $54 \%$ of them prefer recycled IT equipment for their own personal use. Although the use of recycled IT equipment is lower than other actions, $54 \%$ is quite significant. For Indonesia's people, the cost of IT equipment is relatively expensive compared to their living standard and perhaps this is the reason that half of the respondents are willing to use recycled items.

In this section, all demographic variables have no statistically significant impact on respondents' Green IT practice.

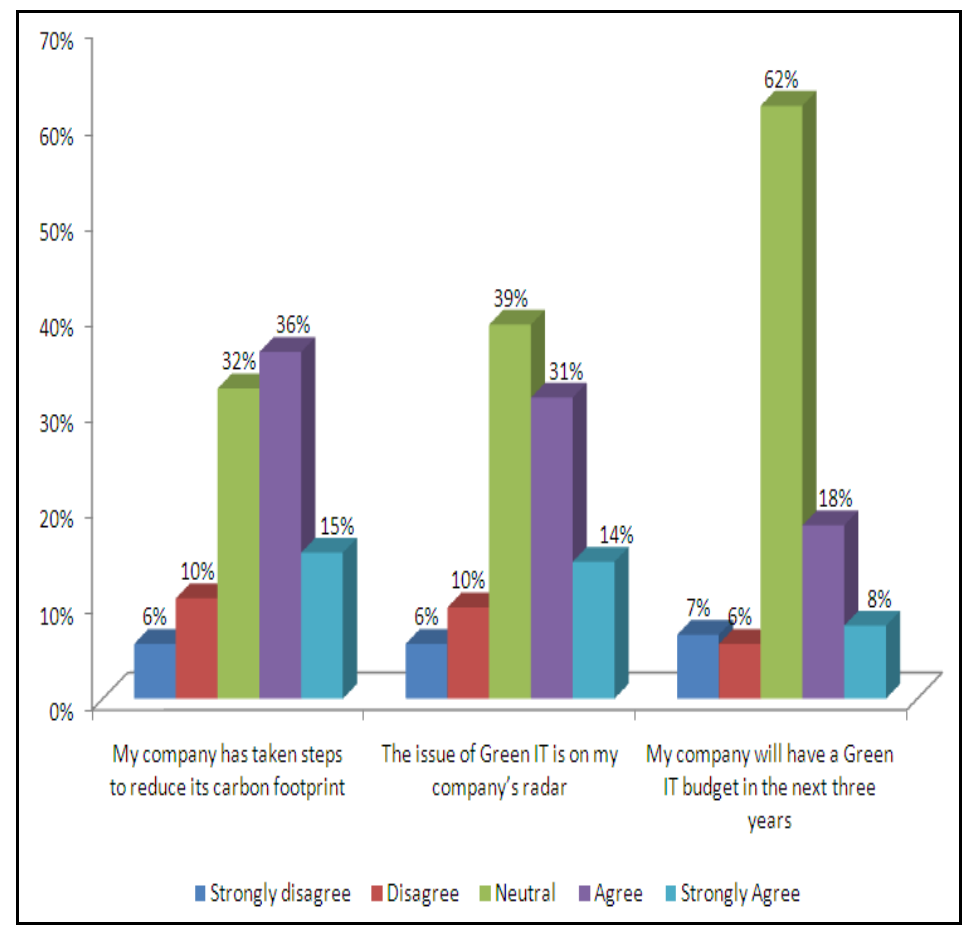

Figure 10. Green IT Commitment 
After examining the Green IT awareness, knowledge, practice and recognition of the IT professional's role to lead changes in Green IT, the respondents were asked to identify their company's commitment to reduce its carbon footprint.

Based on the result on Figure 11, 51\% of the companies' respondents have taken steps to reduce their carbon footprint. Although industry difference does not significantly affect this finding, manufacturing companies and the IT industry appear to lead the rest.

Less than $50 \%$ of the respondents agreed that the issue of Green IT is on their company's radar. This means that although some companies have taken steps to reduce their carbon footprint, the issue of Green IT is yet to emerge as part of the overall strategy for many companies.
Figure 11 shows that less than 10\% of respondents strongly believe that their companies will have a Green IT budget in the next three years. More than 50\% chose a neutral response to this question which can be interpreted as a lack of awareness about budget allocation.

Based on these statistical results, manufacturing and communication companies in Indonesia tend to include the Green IT issue on their company's radar more than other industries. Companies in the IT and manufacturing sectors are more likely to have a Green IT budget allocation in the next three years. Furtheremore, there is no statistically significant difference in those three questions about Green IT commitment.

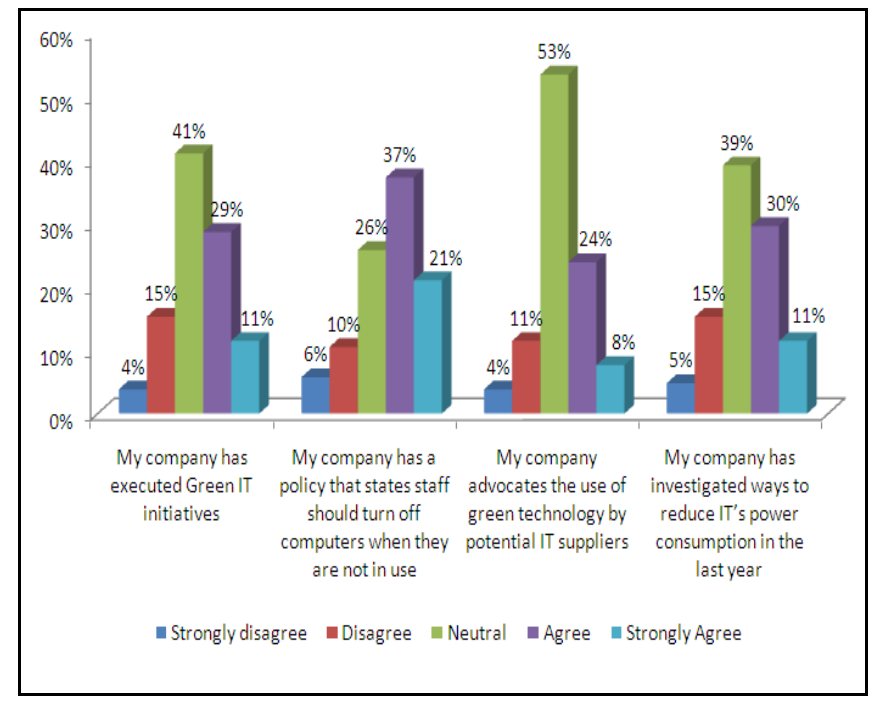

Figure 11. Actions to Green IT

The initiation of Green IT by companies was also assessed. According to respondents only $40 \%$ of companies have executed Green IT initiatives and more than $50 \%$ of the companies have a policy to turn off computers when they are not in use. This explains the result on Figure 12, which shows that most of the respondents have got used to turning off computers as part of Green IT practice. In addition, most companies do not seem to track the Green credentials of their suppliers. However, more than $40 \%$ have explored ways to reduce IT power consumption.

These views are not sensitive to differences in participants' age, gender, occupation, education or industry. However, companies in the manufacturing industry tend to have more Green IT actions in their policy, selecting suppliers and reducing IT power consumption. On the other hand, companies in Trade (retail and wholesale) sector are less likely to have Green IT initiatives. Overall, the respondents are less positive of Green IT actions. 


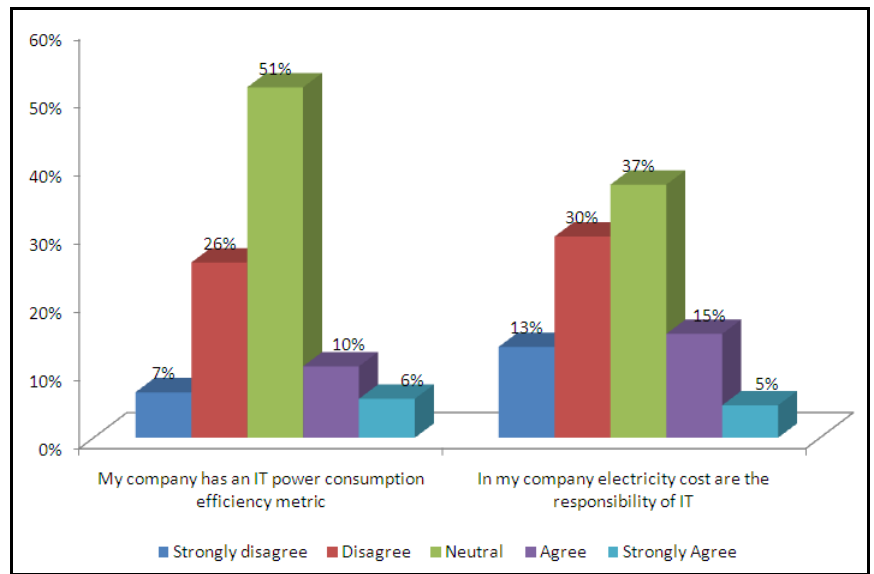

Figure 12. Green IT Governance

In Figure 13, the survey further explored Green IT governance related to practices that companies might have put in place. The majority of respondents were not aware nor disagreed with the use of the IT power consumption efficiency metric.

Moreover, based on the result, electricity costs are not part of an IT department's responsibility in most of the respondents' companies. These views are also not sensitive to demographical profiles, however, companies in the health industry tend to use IT power consumption efficiency metrics whereas the mining industry does not. Electricity costs are the responsibility of IT departments in many communication companies but not in consulting companies.

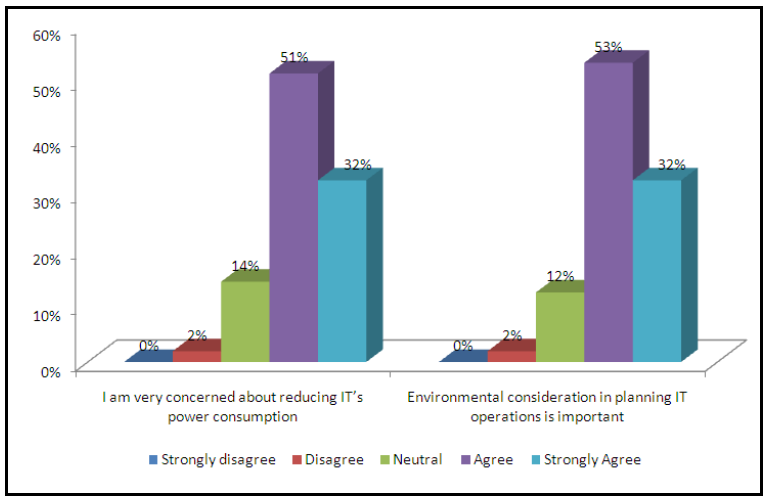

Figure 13. Personal Commitment

Finally, despite the gap between the level of awareness and action toward IT contribution to gas emissions as well as low ranks of existing Green IT governance, Figure 14 shows that $84 \%$ are personally concerned about reducing IT power consumption and $85 \%$ believe that environmental considerations in planning IT operations are important. No significant difference was found in those questions; however people who work as database and system administrators, as well as IT security specialists tend to have more personal commitment compared to people who work as business and system analysts and in other positions.

\section{International Comparison}

In order to obtain more understanding of the findings in this study, some of the results were benchmarked against the 
results of an Australian Green IT Attitude and Action Survey, conducted by RMIT (2009), and a global Green IT Attitude and Action Survey, conducted by Info Tech
(2008). However, due to copyright issue, we only show the outcome our survey in Indonesia which is encapsulated in Table III.

Table III: A Perception and Practices of Green IT Indonesian Corporations

\begin{tabular}{|l|l|}
\hline & $\begin{array}{l}\text { Source: Own } \\
\text { survey* }\end{array}$ \\
\hline Item & Indonesia \\
\hline Concern about climate change & $94 \%$ \\
\hline $\begin{array}{l}\text { Company action for reducing } \\
\text { carbon footprint }\end{array}$ & $51 \%$ \\
\hline Green IT on company's radar & $46 \%$ \\
\hline $\begin{array}{l}\text { Budget for green IT in the next } \\
3 \text { years }\end{array}$ & $26 \%$ \\
\hline $\begin{array}{l}\text { Company's steps to reduce IT's } \\
\text { power consumption }\end{array}$ & $41 \%$ \\
\hline $\begin{array}{l}\text { Company policy on computers } \\
\text { use }\end{array}$ & $58 \%$ \\
\hline $\begin{array}{l}\text { Company advocating use of } \\
\text { Green technology in sourcing }\end{array}$ & $31 \%$ \\
\hline $\begin{array}{l}\text { Adoption of IT power } \\
\text { consumption efficiency metric }\end{array}$ & $16 \%$ \\
\hline $\begin{array}{l}\text { IT's responsibility for power } \\
\text { consumption }\end{array}$ & $20 \%$ \\
\hline $\begin{array}{l}\text { Personal concern for reducing } \\
\text { IT's power consuption }\end{array}$ & $84 \%$ \\
\hline * Percentage are exact figures & \\
\hline $\begin{array}{l}\text { All percentages refer to those that either "agree" or } \\
\text { "strongly agree" }\end{array}$ \\
\hline
\end{tabular}

Table III indicates that Indonesian respondents are strongly concerned about climate change; similar percentages were also obtained in other regions. This is unsurprising considering the tremendous growth in sentiment towards environmental issues around the world over the last several years, including Indonesia. Indonesian corporations have taken more action to reduce their carbon footprint than other countries. This result might lead to the conclusion that Indonesia has just started to implement environmental strategy while other countries have already set up different actions over the past few years. Alternatively, it indicates time differences between the current (2010), the Australian (2009) and the Global (2008) studies.

However, Indonesian respondents' doubts toward their company's commitment on Green IT, contrasts with the respondents in other countries. The commitment includes whether or not their companies have taken notice of the issue as well as allocated a budget for such initiatives.

Similar results are visible regarding corporations' reduction of IT power consumption and their policy on computer use; yet the percentages are still low for all regions. While respondents in Asia lay claims to IT energy efficiency metrics in about $40 \%$ of their companies, the rest of the world lags behind, including Indonesia $(16 \%)$, even though it is still slightly higher than Australia (14\%).

The same story applies when respondents were asked if electricity costs were the responsibility of IT, results are similar to those when metrics are in place. Again, Asia leads by $45 \%$, while the rest of the world lags behind, including Indonesia at 20\%, while Australia rounds out the bottom at $8 \%$. 
Finally, Indonesian respondents' personal concern for reducing IT power consumption equaled the high results of the rest of the world at $84 \%$, higher than Australia at 64\%.

To conclude, despite the current findings showing no significant difference between Indonesia and other regions in the world, the time difference should be taken into consideration assuming that the results might be affected by behavior and awareness changes within this period. The findings nevertheless indicate that Indonesia underperforms in many dimensions in terms of attitude and action towards Green IT.

However, considering the gaps between attitude and action, Indonesian corporations are willing to learn more and implement strategy specifically to save costs. Increasing oil prices and fierce competition will be the driving force to adopt such initiatives.

\section{Research Limitation}

\section{Geography}

The survey has been mostly distributed to IT professionals in Jakarta and in a country with such economic and technologic disparities, it would be valuable to invite those who live in other regions and big cities such as Surabaya (East Java), Balikpapan (East Kalimantan), and Padang (West Sumatra), where many big companies have direct involvement in environmental policy.

\section{Industry}

In terms of industry, the results show that more than $50 \%$ of respondents come from IT, Education and research industry. However, only $10 \%$ or less of the respondents participate in other industries. This could have inflated the findings especially as only a small percentage come from industries that have direct involvement in environmental policy such as mining or utility companies.

\section{Timeline}

As the three surveys used for the international comparison were conducted in different years (2008, 2009 and 2010), it can be assumed that the timeline's difference might affect the findings. Behavior and even actions towards environmental issues and Green IT particularly have evolved rapidly since 2008, and new trends and initiatives would have obviously influenced the answers of the respondents.

\section{Recommendation}

\section{Timeline and Geography}

For further research, it is recommended that similar surveys be conducted within the same year in order to avoid any difference in the findings due to the time line. This research could be repeated every year to demonstrate the improvement of awareness level in each country.

Secondly it would be valuable to use the online survey model in order to spread the questionnaire to other countries with the help and support of other universities or companies that have an interest in Green IT.

\section{Increasing the Awareness and Reducing Inhibiting Factors}

Based on the study, we have seen a gap between awareness and action; therefore, further studies need to be carried out to find key success factors to increase the awareness level and strategy to implement Green IT.

\section{Measurement/Assessment/Readiness}

Finally, further research could also be done to measure the readiness of Indoensian companies for Green IT implementation. Moreover, analysis on the readiness for each phase of the Green IT life cycle might be usefull to know the position of each company. However our current study has shown that the usage phase is most likely to be the first focus.

\section{Conclusion}

Now more than ever, climate change and energy consumption are at the heart of international discussions and even if Green IT is still a niche market for governmental 
initiatives, the time is coming for industries, agencies and individuals to consider Green IT seriously and spread awareness across the world.

This study has to be considered as a preliminary result and more studies are needed to improve opinion and action towards Green IT. A further study will also be under taken to assess the Green IT readiness index of companies in Indonesia. A further detailed framework will be developed.

\section{References}

Ackoff, R. L. (1967). "Management Misinformation Systems," Management Science, 14 (4), 147-156.

Department of Finance and Deregulation (2010). "ICT Reform Program," [Online], [Retrieved on June 30th, 2010], http://www.finance.gov.au/e-

government/strategy-and-governance/ictreform-program.html

European Commission (2008). Code of Conduct on Data Centers Energy Efficiency Version 1.0, Directorate-General, Joint Research Centre, Institute for Energy, Renewable Energies Unit

Foster, P. (2010). "Green ICT Climbs the Business Agenda in Australia," [Online], [Retrieved July 30th 2010], http://www.thegreenitreview.com

Global Green IT Attitude \& Action Survey, (2008). Info Tech

Ministry of Finance (2009). "Economic and Fiscal Policy Strategies for Climate Change Mitigation in Indonesia," Ministry of Finance and Australia Indonesia Partnership, Jakarta

Molla, A. (2008). "GITAM: A Model for the Adoption of Green IT", Proceeding of the Australasian Conference on Information Systems, 3-5 December 2008, Christchurch.

Molla, A., Pittayachawan, S. \& Corbitt, R. (2009). "Green IT Diffusion: An International Comparison," School of
Business Information Technology, RMIT University.

National IT and Telecom Agency (2008). Green IT Guidelines for Public Authorities,

Nunnally, J. C. (1978). Psychometric Theory, McGraw Hill

The Environmental Protection Agency, [Online], [Retrieved on June 30th, 2010], http://www.epa.gov 